\title{
PERILAKU REMAJA PUTRI DALAM PEMERIKSAAN PAYUDARA SENDIRI (SADARI) DI TINGKAT II AKADEMI KEBIDANAN PALUTA HUSADA GUNUNG TUA TAHUN 2015
}

\author{
Ica Fauziah Harahap \\ Staf Pengajar Program Studi D III Kebidanan Yayasan Pendidikan Paluta Husada
}

\begin{abstract}
Abstrak
Pemeriksaan payudara sendiri (SADARI) adalah pemeriksaan payudara sendiri untuk dapat menemukan adanya benjolan abnormal. Dengan melakukan SADARI atau pemeriksaan payudara sendiri, kanker payudara dapat di temukan secara dini.Menurut WHO Sebanyak 1,7 juta wanita didiagnosis menderita kanker payudara pada tahun 2012. Di indonesia menurut Depkes RI, 2013 angka kejadian kanker payudara di indonesia sebanyak 26 per 100.000 perempuan. Sementara di Dari data Medical Record rumah sakit umum pusat Haji Adam Malik Medan tahun 2012, jumlah pasien yang menderita kanker payudara ada sebanyak 1.305 orang di sebabkan oleh kurangnya pengetahuan dalam pencegahan kanker payudara yaitu dengan cara pemeriksaan payudara sendiri (SADARI). Tujuan peneliti ini adalah untuk mengetahui Perilaku Remaja Putri Dalam pemeriksaan payudara sendiri (SADARI). Jenis penelitian ini bersifat deskriptif. Data yang di kumpulkan data primer dan data sekunder. Populasi dalam penelitian ini adalah seluruh remaja putri tingkat II Akademi Kebidanan Paluta Husada Gunung Tua tahun 2015 sebanyak 47 orang. Sampel dalam penelitian ini yaitu 33 Orang remaja putri dengan Pengambilan sampel (sampling) di lakukan secara Purposive Sampling. Dari hasil penelitian diperoleh berdasarkan kategori perilaku remaja putri dalam pemeriksaan payudara sendiri (SADARI) secara umum menunjukkan mayoritas remaja putri mempunyai pengetahuan kurang yaitu sebanyak 25 orang $(75,8 \%)$. Berdasarkan kategori sikap,bersikap positif sebanyak 32 orang $(96,9 \%)$. Dan berdasarkan kategori Tindakan,Mayoritas Remaja putri memiliki Tindakan Tidak sebanyak 20 orang $(60,6 \%)$. Di harapkan pada responden agar banyak membaca dan mencari informasi tentang kesehatan khususnya dalam pemeriksaan payudara sendiri (SADARI).
\end{abstract}

Kata Kunci : Pengetahuan, Sikap, Tindakan, Pemeriksaan Payudara Sendiri

\section{PENDAHULUAN}

Payudara adalah alat vital dan kebanggan dari setiap wanita. Banyak wanita yang menginginkan mempunyai payudara yang indah, padat, dan kencang sehingga membuat dirinya menjadi lebih percaya diri. Yang mempunyai payudara kecil, akan berusaha sekuat tenaga agar payudaranya .Namun, kebanggaan itu tentu akan musnah jika ada gangguan yang terjadi pada payudaranya (Pamungkas,2011).

Pemeriksaan payudara sendiri (SADARI) adalah pemeriksaan payudara sendiri untuk dapat menemukan adanya benjolan abnormal. Dengan melakukan SADARI atau pemeriksaan payudara sendiri, kanker payudara dapat di temukan secara dini. Deteksi dini dapat menekan angka kematian sebesar 25-30\% (Mulyani,2013).

World health Organization (WHO) mengatakan selalu ada kasus baru terkait kanker payudara.Data menunjukkan terjadi peningkatan pada kasus kanker payudara. Sebanyak 1,7 juta wanita didiagnosis menderita penyakit ini pada tahun 2012. Kanker payudara ini menjadi penyebab paling umum kematian dikalangan wanita (Kusmiyati,2013).
Kanker payudara merupakan "kanker peringkat kedua " yang paling banyak diderita dan ditakuti wanita. Data rekapitulasi kasus kanker tertinggi dari dinas kesehatan kota medan sepanjang 2014 yakni kaker payudara sebanyak 449 kasus.Dari data Medical Record rumah sakit umum pusat Haji Adam Malik Medan tahun 2012, jumlah pasien yang menderita kanker payudara ada sebanyak 1.305 orang dan pasien kanker payudara yang menjalani kemoterapi ada sebanyak 540 orang (Hariansib, 2014).

Deteksi dini merupakan langkah awal terdepan dan paling penting dalam pencegahan kanker. Dengan deteksi dini diharapkan angka mortalitas dan morbiditas, dan biaya kesehatan akan lebih rendah. Deteksi dini dan skrining menjadi kunci tingkat bertahan hidup yang tinggi pada penderita. Deteksi dini dapat menekan angka kematian sebesar 25-30\%. Deteksi dini sangat penting dan efektif dalam menanggulangi kanker payudara (Milda, 2012)

Bagaimana Perilaku Remaja Putri dalam Pemeriksaan Payudara Sendiri (SADARI) di Tingkat II Akademi Kebidanan Paluta Husada Gunung Tua tahun 2015 ? 


\section{TUJUAN PENELITIAN}

Mengetahui Perilaku Remaja Putri dalam Pemeriksaan Payudara Sendiri (SADARI) di Tingkat II Akademi Kebidanan Paluta Husada Gunung Tua Tahun 2015.

\section{MANFAAT PENELITIAN}

1. Bagi tempat penelitian Meningkatkan pengetahuan remaja putri tentang SADARI agar mampu mengaplikasikannya dalam kehidupan sehari-hari.

2. Bagi penulis

Sebagai salah satu prasyarat kelulusan dalam menyelesaikan program Diploma III Kebidanan, menambah keterampilan bagi penulis dalam melakukan penelitian serta dapat menambah wawasan tentang perilaku remaja putri dalam pemeriksaan Payudara Sendiri

SADARI ) .

3. Bagi Instansi pendidikan

Hasil penelitian ini dapat di gunakan sebagai bahan tambahan bacaan di perpustakaan Akademi kebidanan Paluta Husada Gunung Tua.

\section{METODE}

\section{Jenis Penelitian}

Jenis penelitian ini adalah menggunakan penelitian deskriptif yaitu untuk mengetahui Perilaku Remaja Putri Dalam pemeriksaan payudara sendiri (SADARI) di tingkat II Akademi Kebidanan Paluta Husada Tahun 2015.

\section{Lokasi dan Waktu Penelitian}

Lokasi penelitian dilakukan di tingkat II Akademi Kebidanan Paluta Husada Gunung Tua Tahun 2015. Penelitian ini dilakukan pada bulan Mei - Juni 2015.

\section{POPULASI DAN SAMPEL}

\section{Populasi}

Populasi dalam penelitian ini adalah seluruh remaja putri tingkat II Akademi Kebidanan Paluta Husada Gunung Tua yang berjumlah 47 orang.

Sampel

Jumlah sampel dalam penelitian ini yaitu sebanyak 33 orang dengan pertimbangan sampel yang memenuhi syarat berusia 20 tahun atau lebih.

\section{METODE PENGUMPULAN DATA}

\section{Data Primer}

Data primer adalah data yang diperoleh langsung dari subjek peneliti dengan menggunakan alat pengukuran atau alat pengumpulan data (wawancara dan kuesioner).

\section{Data Sekunder}

Data sekunder yaitu data yang diperoleh dari pihak lain/tidak langsung diperoleh peneliti dari subjek penelitiannya. Data sekunder pada penelitian ini diperoleh dari pihak akademi kebidanan Paluta Husada yang berupa absensi tingkat II Akademi Kebidanan Paluta Husada Gunug Tua Tahun 2015.

\section{TEKNIK PENGOLAHAN DATA}

Data yang telah terkumpul di olah dengan cara manual dengan langkah sebagai berikut :

1. Proses editing ( pengeditan )

Di lakukan pengecekan kelengkapan data yang telah terkumpul.

2. Coding (pengkodean)

Setelah data di periksa kemudian memberi kode angka dari setiap jawaban responden sesuai dengan variabel yang di teliti dan mengelompokkannya untuk mempermudah pengolahan data

3. Scoring (pemberian skor)

Melakukan pemeriksaan terhadap jawaban responden yang ada dan memberikan skor yang di peroleh pada kuesioner, lalu mengelompokan sesuai kategori pengetahuan.

4. Tabulating (tabulasi)

Untuk mempermudah analisa data pengolahan data serta pengambilan kesimpulan dan data tersebut di masukan ke dalam bentuk distribusi frekuensi.

\section{METODE}

Analisis data penelitian merupakan media untuk menarik kesimpulan dari seperangkat data hasil pengumpulan.Analisa data di lakukan Secara Deskriftif dengan Mengambarkan Seluruh Hasil penelitian sacara lengkap dan di sajikan dalam bentuk tabel distribusi frekuensi. Yaitu menggunakan analisis univariat,dimana data yang di peroleh dari hasil pengumpulan dapat di sajikan dalam bentuk tabel distribusi frekuensi, ukuran tendensi sentral atau grafik (Saryono, 2010)

\section{HASIL DAN PEMBAHASAN}

Perilaku remaja Puteri Dalam Pemeriksaan Payudara Sendiri (SADARI) berdasarkan Pengetahuan dan sikap

Berdasarkan tabulasi silang pengetahuan dan sikap remaja puteri dalam pemeriksaan payudara sendiri (SADARI) di dapatkan hasil bahwa Mayoritas Remaja putri berpengetahuan cukup dengan bersikap positif sebanyak 5 orang $(100 \%)$, dan minoritasnya responden memiliki pengetahuan kurang dengan sikap Negative sebanyak 1 orang (4\%).

Menurut pendapat Sarwono yang di kutip Maulana (2012) bahwa sikap seseorang dapat berubah dengan di perolehnya tambahan informasi tentang objek 
tertentu melalui persuasi serta tekanan dari kelompok sosialnya.

Berdasarkan uraian di atas, penulis menyimpulkan bahwa pengetahuan mempengaruhi sikap remaja puteri dalam pemeriksaan payudara sendiri, karena semakin tinggi pengetahuan seseorang maka semakin positif sikap seseorang terhadap suatu perilaku kesehatan.

\section{Perilaku remaja Puteri dalam Pemeriksaan Payudara Sendiri (SADARI) berdasarkan Sikap dan Tindakan}

Berdasarkan tabulasi silang Sikap dan Tindakan remaja puteri dalam Pemeriksaan Payudara Sendiri (SADARI) di dapatkan hasil bahwa Mayoritas Remaja putri bersikap Positif dengan tindakan kategori Tidak sebanyak 19 orang $(59,4 \%)$ dan minoritasnya responden memiliki Sikap Positif dengan tindakan Ya sebanyak 13 orang $(40,6 \%)$.

Menurut pendapat Bloom yang di kutip oleh Notoatmodjo (2010), bahwa perilaku seseorang sangat kompleks dan mempunyai bentangan yang sangat luas. Kemudian perilaku di kembangkan menjadi 3 tingkat yaitu pengetahuan (knowledge), sikap (Attitude), dan tindakan (Practice). Sikap belum tentu terwujud dalam tindakan, sebab untuk terwujudnya tindakan perlu faktor lain, yaitu antara lain adanya fasilitas atau sarana dan prasarana.

Berdasarkan Pernyataan Di atas, penulis berasumsi bahwa sikap belum tentu terwujud dalam suatu tindakan. Sikap tidak selalu mempengaruhi tindakan seseorang untuk melakukan suatu tindakan kesehatan. Karena tindakan dapat terwujud juga dengan beberapa faktor lain seperti : Tradisi, lingkungan, serta fasilitas atau sarana dan prasarana.

\section{Perilaku remaja Puteri dalam Pemeriksaan Payudara Sendiri (SADARI) berdasarkan Pengetahuan dan Tindakan}

Berdasarkan tabulasi silang pengetahuan dan Tindakan remaja puteri dalam Pemeriksaan Payudara Sendiri (SADARI) di dapatkan hasil bahwa Mayoritas Remaja putri berpengetahuan kurang dengantindakan kaegori Tidak sebanyak 20 orangdan minoritasnya responden memiliki pengetahuan kurang dengantindakan Ya sebanyak 5 orang (20\%).

Menurut Green yang di kutip oleh Febriani (2012) bahwa faktor tindakan di bentuk oleh beberapa faktor antara lain, faktor predisposisi yaitu faktor yang mempermudah atau mempredisposisi terjadinya tindakan seseorang antara lain pengetahuan, sikap, keyakinan, kepercayaan, nilai-nilai dan tradisi.

Berdasarkan teori di atas, menurut asumsi penulis bahwa pengetahuan mempengaruhi tindakan seseorang dalam melakukan suatu perilaku. Karena semakin tinggi pengetahuan seseorang maka semakin baik tindakan seseorang dalam melakukan Tindakan SADARI.

\section{Kesimpulan}

Berdasarkan Tujuan Penelitian, maka dapat di simpulkan sebagai berikut:
1. Berdasarkan kategori pengetahuan Remaja putri dalam pemeriksaan payudara sendiri (SADARI) responden yang berpengetahuan Baik sebanyak 4 orang $(9,1 \%)$, yang berpengetahuan cukup sebanyak 5 orang $(55,1 \%)$, dan berpengetahuan kurang 25 orang $(75,8 \%)$.

2. Berdasarkan Kategori Sikap remaja putri dalam pemeriksaan payudara sendiri (SADARI) Mayoritas Remaja putri bersikap positif sebanyak32 orang $(96,9 \%)$,dan minoritasnya responden memiliki sikap Negative sebanyak 1 orang $(3,1 \%)$.

3. Berdasarkan Kategori Tindakan remaja putri dalam pemeriksaan payudara sendiri (SADARI) Mayoritas Remaja putri memiliki TindakanTidak sebanyak 20 orang $(60,6 \%)$, dan Minoritas Remaja puteri memiliki tindakan Ya sebanyak 18 orang $(39,4 \%)$.

4. Berdasarkan tabulasi silang pengetahuan dan sikap remaja puteri dalam pemeriksaan payudara sendiri (SADARI) di dapatkan hasil bahwa Mayoritas Remaja putri berpengetahuan cukup dengan bersikap positif sebanyak 5 orang $(100 \%)$, dan minoritasnya responden memiliki pengetahuan kurang dengan sikap Negative sebanyak 1 orang (4\%).

5. Berdasarkan tabulasi silang Sikap dan Tindakan remaja puteri dalam Pemeriksaan Payudara Sendiri (SADARI) di dapatkan hasil bahwa Mayoritas Remaja putri bersikapPositif dengan tindakan kategori Tidak sebanyak 19 orang $(59,4 \%)$ dan minoritasnya responden memiliki Sikap Positif dengan tindakan Ya sebanyak 13 orang $(40,6 \%)$.

6. Berdasarkan tabulasi silang pengetahuan dan Tindakan remaja puteri dalam Pemeriksaan Payudara Sendiri (SADARI) di dapatkan hasil bahwa Mayoritas Remaja putriberpengetahuan kurang dengantindakan kaegori Tidak sebanyak 20 orangdan minoritasnya responden memiliki pengetahuan kurang dengantindakan Ya sebanyak 5 orang $(20 \%)$.

\section{Saran}

Dari hasil penelitian yang di lakukan penulis mengemukakan saran sebagai berikut:

1. Penulis Selanjutnya

Di harapkan bagi penulis selanjutnya lebih di kembangkan dengan menggunakan sampel yang lebih luas, dan referensi yang lebih baru dan lebih banyak sehingga di peroleh hasil yang lebih baik terhadap pengetahuan Remaja putri dalam pemeriksaan payudara sendiri (SADARI).

2. Tempat penulis

Di harapkan bisa menjadi bahan masukan dalam meningkatkan pengetahuan remaja putri dalam pemeriksaan payudara sendiri (SADARI). 
3. Instansi Pendidikan

Di harapkan dapat menjadi bahan masukan bagi institusi pendidikan untuk meningkatkan pengetahuan remaja putri dalam pemeriksaan payudara sendiri (SADARI), dan sumber informasi maupun bahan bacaan bagi penelitian lain yang tertarik untuk melakukan penelitian lanjutan.

4. Bagi Responden

Di Harapkan Dapat menjadi bahan masukan pada Tingkat II Akademi Kebidanan Paluta Husada Gunung Tua dalam meningkatkan Pengetahuan remaja putri dalam pemeriksaan payudara sendiri (SADARI).

\section{DAFTAR PUSTAKA}

Marmi, 2014, Kesehatan Reproduksi, Pustaka Belajar, Yogyakarta

Maulana Heri DJ, 2009, Promosi Kesehatan, EGC, Jakarta

Mubarak, 2011, Promosi Kesehatan, EGC, Jakarta

Mulyani NS \&nuryani, 2013, kanker payudara dan

PMS pada kehamilan, Nuha Medika, yogyakarta
Notoatmodjo s, 2010, Promosi Kesehatan, Rineka Cipta , Jakarta

Notoatmodjo S, 2010, Metode Penelitian Kesehatan, Rineka Cipta, Jakarta

Notoatmodjo S, 2009, Pendidikan Dan Perilaku Kesehatan, Rineka Cipta, Jakarta

Pamungkas Z, 2011, deteksi dini kanker payudara, Buku Biru, yogyakarta

Riyanto Agus, 2011, Metodologi Penelitian Kesehatan, Nuha Medika, Yogyakarta

Saryono, 2010, Metode Penelitian Kebidanan,DIII,DIV,SI dan S2, Nuha Medika, Yogyakarta

Setiati eni,2009, waspadai 4 kanker ganas pembunuh wanita, ANDI yogyakarta, yogyakarta.

Syaifuddin, 2009, Anatomi fisiologi, EGC, Jakarta Widyastuti yani,dkk,2009, kesehatan Reproduksi, Fitramaya,Yogyakarta 